\title{
Tunnel Monitoring and Measurement Case Study in Qiyueshan Tunnel
}

\author{
Chunjin Lin ${ }^{1, a}$, Lun Zhou ${ }^{1, b}$, Shucai $\mathrm{Li}^{1, \mathrm{c}}$, Zhenhao $\mathrm{Xu}^{1, \mathrm{~d}^{\star}}$, Liping $\mathrm{Li}^{1, \mathrm{e}}$, \\ Jing $\mathrm{Wu}^{1, \mathrm{f}}$, Yanhuan Zhang ${ }^{1, \mathrm{~g}}$
}

${ }^{1}$ Geotechnical \& Structural Engineering Research Center, Shandong University, Jinan, Shandong 250061, China

\author{
alinchunjin@sdu.edu.cn, ${ }^{b} 18769788330 @ 163 . c o m,{ }^{c}$ lishucai@sdu.edu.cn, \\ d, ${ }^{*}$ zhenhao_xu@sdu.edu.cn, ${ }^{e}$ yuliyangfan@163.com, ${ }^{\dagger}$ wujing9516@163.com, \\ gzhangyanhuanlei@163.com
}

\begin{abstract}
Keywords: Monitoring and measuring, Vault subsidence, level of convergence, Construction safety. Abstract. Monitoring and measuring is one of three main factors of the New Austrian Tunneling Method. By measuring the tunnel rock deformation data, collecting and analyzing it, measuring data can be used for the feedback of excavation results and for guiding the construction timely. The tunnel monitoring includes monitoring methods, monitoring equipment, data processing analysis, and through data analysis and feedback to guide the construction. Tunnel monitoring and measurement is carried out at Qiyueshan tunnel site in the present study. By processing and evaluating the vault settlement and surrounding displacement measurement data of the tunnel section, the deformation characteristics and development trend of the tunnel rock is analyzed. Thus, the design and construction of the tunnel is amended and optimized. The stability of the tunnel is forecast and ensured. The result of monitoring and measuring in the Qiyueshan tunnel was effect. And it avoided big accident caused by the landslides or the large deformation of the supporting structure due to excessive deformation of the surrounding rock. The present monitoring and measurement method can be used to monitor other tunnels.
\end{abstract}

\section{Introduction}

The New Austrian Method (New Austrian Tunneling Method, referred to as 'NATM') is the most common method in tunnel construction. Monitoring and measuring is one of the important components of the NATM [1]. At present, the study of complex stress state of surrounding rock in detail and the corresponding response is difficult, the effective way is the implementation of site monitoring measurement in the process of the implementation of such projects [2, 3]. Tunnel monitoring and measuring mainly includes vault sink, clearance changes and so on. Its purpose include: (1) to ensure the long-term stability of the structure and the construction safety [4]; (2) to verify the effect of supporting structure, to confirm the accuracy of the support parameters and construction methods [5]; (3) to provide the basis for adjusting support parameters and construction methods; (4) to determine the appropriate time of the secondary lining; (5) to provide the basis for design and informatization construction by accumulating the measured data. The site of Qiyueshan tunnel is full of fracture and karst, and there is even some mud in it, so the integrity of the surrounding rock is poor and the intensity is low. In the karst development area, construction process which is prone to landslides and large deformation of retaining structure, and so on, seriously threatens the safety of construction person, therefore, it is necessary to carry out the work of tunnel monitoring measurement [6]. Measuring the displacement of tunnel surrounding and vault subsidence displacement, the construction can be guide correctly according to the change of the displacement $[7,8,9]$. Compared with the traditional tunnel monitoring and measurement, the Qiyueshan use a convergence ruler to measure the length of the triangle side, which is made by the three monitor points arranged on the section of the tunnel. Seeking the tunnel horizontal convergence displacement by measuring the length change of the base side of the triangle, seeking the vault settlement displacement by the Helen's formula, processing the measured data by the use of the regression analysis, analysing the processed data by the excel form, the change of the tunnel vault and horizontal displacement of the surrounding can be known to guide the construction $[10,11]$. By working in Qiyueshan tunnel monitoring measurement, it has obtained the good effect, 
and avoided the landslides and large supporting deformation caused by excessive deformation of surrounding rock [12].

\section{Engineering Application}

Qiyueshan tunnel is located in lichuan city, Hubei province, China, between Nanping town and Moudao town. It is designed for cross the Qiyueshan. It is designed to separate the tunnel, the length of the left pieces is $3380 \mathrm{~m}$ and the maximum depth is $670 \mathrm{~m}$; the length of the right pieces is $3282 \mathrm{~m}$ and the maximum depth is $543 \mathrm{~m}$. The tunnel section is $10.5 \mathrm{~m} \times 5.0 \mathrm{~m}$. It belonged to the tunnel erosion denudation construct of the Zhongshan landscape. Tunnel across the ridge, the surface elevation 1100 $\sim 1710 \mathrm{~m}$, was undulating terrain overall. Crossing into the hole where the slope angle of the slope $25^{\circ}$, slope of $120^{\circ}$; tunnel out of the hole where the slope angle of the slope $40^{\circ}$, slope of $313^{\circ}$. Natural slope angle of slope of the tunnel area is generally $20^{\circ} \sim 40^{\circ}$, dissolved ditch, melting tank, funnel, sinkholes and other karst landforms micro. There are two fault in the tunnel site van, namely: (1) groove reverse fault (F1): also called Qiyueshan fracture, parallel to the development of the mountains, to the NE, slightly south east-dipping, pressure resistance. The geophysical of this segment displayed that the rock of the anomaly zone is broken, the drilling also showed that segment extrusion tectonics resulted in rock cataclasites distinctive characteristics. (2) Desheng field tomography (F2): roughly parallel with the mountains, Shunde wins through development, to about $54^{\circ}$, in YK21 $+910($ ZK21 + 910) at the intersection with the tunnel, a few meters wide, the geophysical displayed that the segment was broken exception. Two faults in the tunnel hole body performance are narrow, with a substantially vertical line, the karst is rich within the fault zones, there may exist some large caves, they will have a greater impact on the construction of this tunnel.The section headings are in boldface capital and lowercase letters. Second level headings are typed as part of the succeeding paragraph (like the subsection heading of this paragraph).

\section{Monitoring Methods}

Monitoring Purposes. After the underground excavation, convergence is the most direct and obvious arguments reflected in the surrounding rock and the supporting structural mechanics with morphological changes. By monitoring the data, the stability of the surrounding rock and the supporting structures can be known from the graph of the data. The cross-section changes can be reflected. The stability of the vault can be decided to prevent landslides or other large deformation of the tunnel surrounding rock.

Monitoring Instruments. A hand drill is used to arrange monitoring point drills. A laser locator is used to determine the drilling location and to ensure that the drilling location is on the same section. Expansion hooks are installed in the borehole and are fixed with cement. Spray paint is marked to facilitate the next measurement. A convergence is used to measuring the data, then writing down the data on the chat.

Measuring Point Layout Principles. Surrounding displacement measuring point and crown settlement measuring points are on the same section. In the same section, the convergence laid baseline should choose a different size arranged in accordance with section excavation methods. In combination with the tunnel method of the project, surrounding convergence displacement measurement section measuring points is shown below in Figure 1. When installing the measuring point on the measured cross-section with the wind or percussion drill rig into the hole, pore size $40-80 \mathrm{~mm}$ depth $20 \mathrm{~cm}$, insert the convergence of embedded parts after filling cement mortar in the hole, try to make the two embedded parts baseline axis direction and the axis of the pin and the hole in a vertical position, having a good protective cap, it can be monitored after the mortar solidifies. 


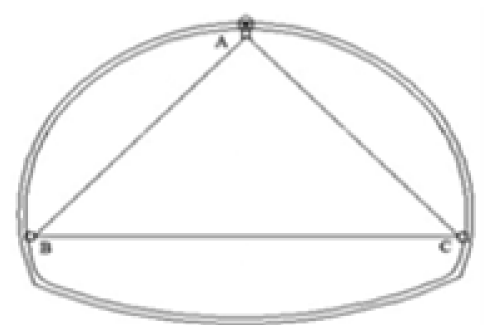

Fig.1 Qiyueshan tunnel surrounding convergence and vault settlement schematic survey lines

Convergence Methods of Observation. (1) The dial indicator readings raised 2.5-3.0cm;

(2) The converge meter ruler hooks were hanging on two measuring points, tighten ruler, the pin is inserted into the appropriate holes on the ruler with the hook to fix it;

(3) Turn the adjusting nut to tighten the ruler to make the observation window lines up with the panel in a straight line;

(4) Read dial ruler in value, the two together is the distance between the measuring point;

(5) After each measurement is completed, loosen the adjusting nut, and then exit the hook, the ruler removed, wipe a good income, and regularly coated with anti-rust oil;

(6) Before and after each survey line the relative displacement can be calculated by subtracting twice the distance between the measuring point ( displacement of tunnel convergence value).

Find the vault displacement by Heron's formula. Heron's formula: As long as the length of the triangle's three sides is known, the triangle area can be solved by the formula. Formula: If the length of the three sides of the triangle are known, respectively as a, b, c, then the area of the triangle

$$
\mathrm{s}=\sqrt{\mathrm{p}(\mathrm{p}-\mathrm{a})(\mathrm{p}-\mathrm{b})(\mathrm{p}-\mathrm{c})}
$$

where $p$ is the perimeter of the triangle, $p=1 / 2(a+b+c)$.

Arranging three points such as point $\mathrm{A}$ 、 point $\mathrm{B}$ 、 point $\mathrm{C}$ in some section of the tunnel. Point $\mathrm{B}$ and point $\mathrm{C}$ are arranged on both sides of the tunnel haunch section, point $\mathrm{A}$ is arranged on the axis of the tunnel vault, point $\mathrm{A}$, point $\mathrm{B}$, point $\mathrm{C}$ are arranged on the same cross-section of the tunnel. After the three points are completed, the side length of $\mathrm{AB}$ as $\mathrm{c}$, the side length of $\mathrm{AC}$ as $\mathrm{b}$, the side length of $\mathrm{BC}$ as a are measured by using a convergence scale. Three consecutive measurements are averaged to reduce the measurement error, to get a more accurate length of the three sides of the triangle $\mathrm{ABC}$. The triangle area can be solved by the Heron formula, the bottle side $\mathrm{BC}$ of the triangle is known, the distance of point $\mathrm{A}$ to side $\mathrm{BC}$ can be solved by the use of the principle of equal area. Measuring the data by using a convergence scale, then solving the distance h1 by the Heron formula, after several time $\mathrm{t}$, repeating the same steps, getting the distance $\mathrm{h} 2$, the result of $\mathrm{h} 2-\mathrm{h} 1$ is the displacement of the vault during this time, the result of ( $\mathrm{h} 2-\mathrm{h} 1) / \mathrm{t}$ is the displacement rate of the vault during this time. So, the vault settlement displacement and displacement sedimentation rate can be solved by measuring the three side edges and using the Heron formula. Measurement accuracy is higher than other instruments because of the use of convergence gauge.

\section{Data Processing Analysis and Examples}

The displacement of the measured data plotted versus time curve can be more intuitive to see the situation surrounding rock displacement, and by observing the characteristic curve, the preliminary judgment of surrounding rock whether it is stabilized or abnormal situation can be known. There could be some accidental errors in the measurement data caused by the environmental impact or human factors when measuring the tunnel, so that the data has a discrete, there can be fluctuations in the scatter plot drawn by the deformation changes over time, the law is not obvious, it is difficult to analyse and judge. It should be carried out according to the site measured data regression analysis to explore the deformation law of development, to guide the construction and production safety. 
When the tunnel horizontal displacement of the convergence rate is of $0.1 \sim 0.2 \mathrm{~mm} /$ day, dome subsidence displacement speed is of $0.1 \mathrm{~mm} /$ day, the surrounding rock can be thought basically stable. For IV and V Grade Rock, the appropriate time of secondary lining based on the measurement results can be decided, it may be put too much load as the secondary lining is applied early.

In the monitoring process, if it is found to be too large or clearance displacement convergence rate no steady trend, structural reinforcement measures should be taken.

If it is found during clearance displacement with a stable trend of convergence speed, the tunnel structure should be determined accordingly initial support and secondary lining ultimate load on the safety of the structure in order to make the right judgments.

If the measured data through a variety of joint counter-analysis later found that safety factor of supporting or secondary lining structure is larger than early, after the designer's consent, the support parameters can be adjusted properly with the similar geological type.

Changes and adjustments to the level of surrounding rock support parameters are necessary for a corresponding measured data and have been approved by the designer.

In the monitoring process, if the clearance displacement was too large or convergence rate had no steady trends, structural reinforcement measures should be taken. Under current highway tunnel construction technical specification requirements, structural reinforcement of the main measures are as follows:

1) Increase the thickness of the shotcrete, or encryption anchor, or to add a steel mesh;

2) Advance facilities the secondary lining, requires checking secondary lining strength by inverse analysis;

3) Advance facilities the invert.

Here the right pieces of Qiyuanshan a tunnel section YK20 +430 is set as a typical case, the monitoring data was analysed and discussed by the monitors. Through the one-month monitoring section, the curve plotted with the time and the displacement according to the measured data are as follows, respectively: Figure 2 the convergence rate of surrounding displacement, Figure 3 subsidence rate of the dome displacement, Figure 4 Displacement time of surrounding convergence, Figure 5 vault settlement time chart, the figure shows the rate of change of displacement and vaults around the subsidence rate is in the overall downward trend, and over time slowly stabilized. The vault settlement and surrounding convergence displacement does not occur in abnormal and is permitted within the normal range. Indicating that the section of rock support arguments are in better position, there will not appear landslides and large deformation and so on. According to the standard rate of displacement of the tunnel industry developed, when the displacement of small changes in the rate of $0.2 \mathrm{~mm} / \mathrm{d}$, the surrounding rock has be stable, the construction of secondary lining can be made. As of December 6, 2014 , YK $20+430$ section of the horizontal convergence cumulative value $9.488 \mathrm{~mm}$, the convergence rate of change is $0.194 \mathrm{~mm} / \mathrm{d}$; vault settlement cumulative value of $9.423 \mathrm{~mm}$, vault settlement rate of change is $0.182 \mathrm{~mm} / \mathrm{d}$, so the section with the secondary lining can be applied to do.

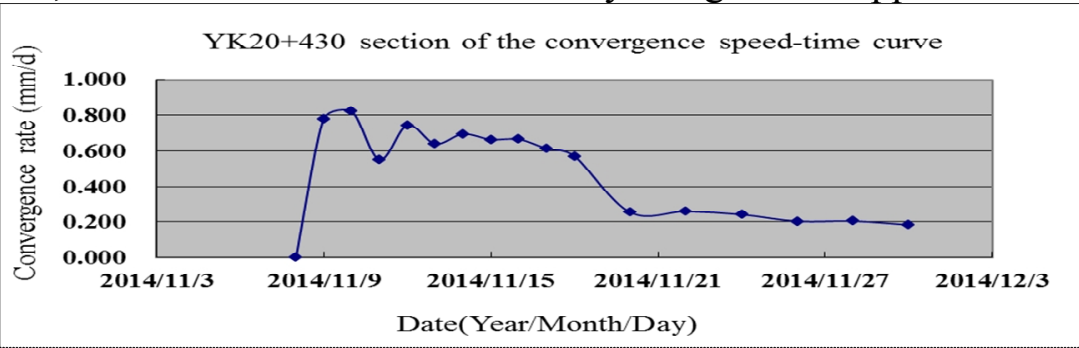

Fig. 2 YK20 +430 section of the convergence speed-time curve 


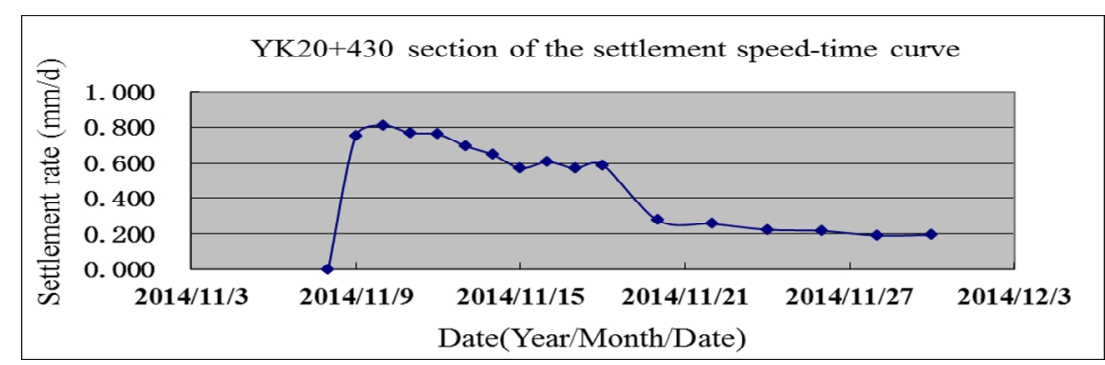

Fig.3 YK20 + 430 section of the settlement speed-time curve

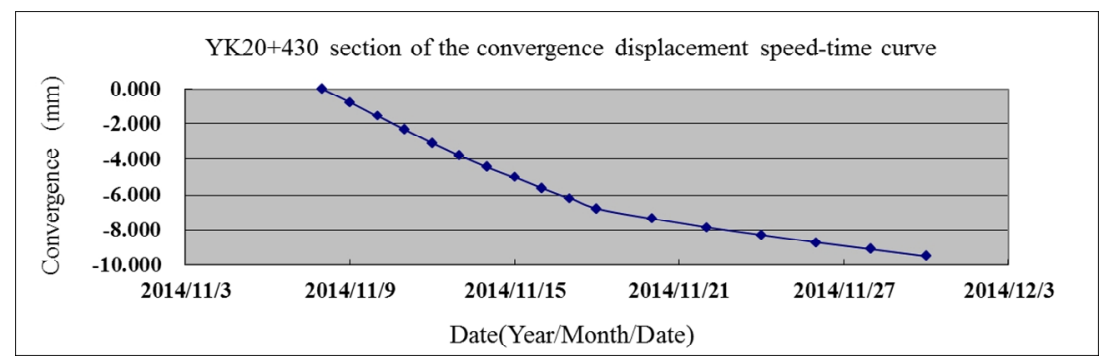

Fig. 4 YK20 + 430 section of the convergence displacement-time curve

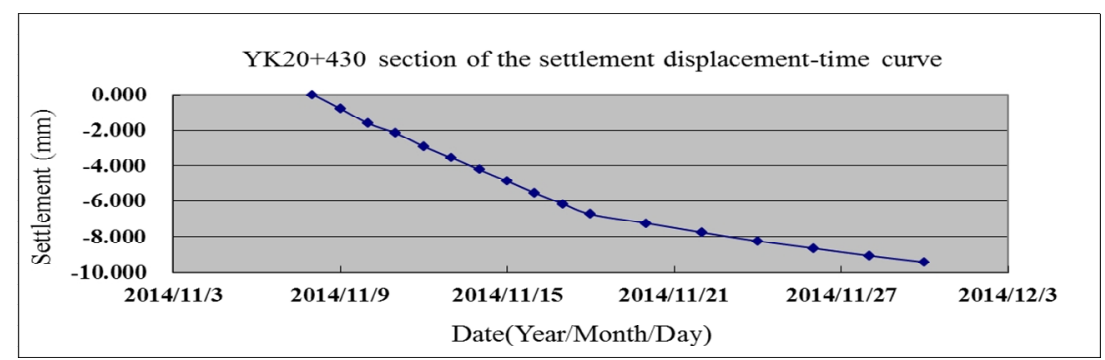

Fig.5 YK20 + 430 section of the settlement displacement-time curve

\section{Summary}

Getting the data through on-site monitoring and measurement, then, processing the measured date, last, plotting the displacement time graph and the rate of change of the displacement graph, the question of the vault displacement settlement and the surrounding displacement convergence can be known clearly .Through on-site monitoring and measurement, the surrounding rock and initial support in the construction of a stable situation and the extent of deformation is analysed. It provides information for the evaluating and modifying of the initial support parameters. Thus, the tunnel construction and the secondary lining time are ensured to be safety enough. The vault settlement displacement can be solved by the use of the Heron's formula, the displacement of the tunnel section can be known only by the use of the convergence ruler. So it reduces the use of other monitoring instruments, improves the monitoring efficiency and reduces the costs. The present monitoring method and monitoring data analysis method also has some positive reference value for the deformation monitoring of other civil engineering projects.

\section{References}

[1] Chen-guang J, Yong H, Jian-guo P. Studies on the Estimation Methods of Vault Displacement of NATM (New Austrian Tunneling Method) Construction[C]//International Seminar on Tunnel and Road Technology. PIARC. 2002.

[2] Jun W, Caichu X, Hehua Z, et al. Site monitoring and analysis of non-symmetrical multi-arch highway tunnel[J]. Chinese Journal of Rock Mechanics and Engineering, 2004, 23(2): 267-271.

[3] MacPherson W N, Silva-Lopez M, Barton J S, et al. Tunnel monitoring using multicore fibre displacement sensor[J]. Measurement Science and Technology, 2006, 17(5): 1180. 
[4] Chung H S, Chun B S, Kim B H, et al. Measurement and analysis of long-term behavior of Seoul metro tunnels using the Automatic Tunnel Monitoring Systems[J]. Tunnelling and Underground Space Technology, 2006, 21(3): 316-317.

[5] Jian-jun M A. Study and Application of the Site Monitoring Measurement of Road Tunnel Construction [J]. Journal of Henan Polytechnic University (Natural Science), 2006, 5: 012.

[6] Liu Z, Li W, Sun M, et al. Monitoring and comprehensive analysis in F 4 section of Wuqiaoling tunnel[J]. Yanshilixue Yu Gongcheng Xuebao/Chinese Journal of Rock Mechanics and Engineering, 2006, 25(7): 1502-1511.

[7] Dai F C, Lee C F, Ngai Y Y. Landslide risk assessment and management: an overview[J]. Engineering geology, 2002, 64(1): 65-87.

[8] Annan J. Forecasting nonlinear time series of surrounding rock deformations of underground cavern based on PSO-SVM[J]. Rock and Soil Mechanics, 2007, 28(6): 1176-1180.

[9] Zhang N, Yuan L, Han C, et al. Stability and deformation of surrounding rock in pillarless gob-side entry retaining[J]. Safety science, 2012, 50(4): 593-599.

[10] Wang C, Wang Y, Lu S. Deformational behaviour of roadways in soft rocks in underground coal mines and principles for stability control[J]. International Journal of Rock Mechanics and Mining Sciences, 2000, 37(6): 937-946.

[11] Shuaiyu C, Weiyuan Z, Qiang Y, et al. Analysis on stability of surrounding rocks of Shuibuya underground plant by three-dimensional fast lagrangian method $[\mathrm{J}][\mathrm{J}]$. Chinese Journal of Rock Mechanics and Engineering, 2003, 7: 000.

[12] ZHANG G, CHEN L, QIAN S, et al. On-site supervision measure and analysis of Damaoshan tunnels with large section and small clear-distance[J]. Yantu Lixue/Rock and Soil Mechanics, 2010, $31(2)$. 